\title{
Recommendation of the Healthcare System of the Chinese Elderly Group with IoT Technology Based on Responsible Innovation
}

\author{
Yaguang Sun, Deana McDonagh, Susan Liepert, Shafagh Hadinezhad, Faithful Oladeji \\ University of Illinois \\ USA
}

\begin{abstract}
Improving value of life has a direct impact on reducing the burden of care for individuals and communities. The Chinese elderly have self-care challenges and need to be a significant investment in human and financial resources to take care of them. Assistive devices may offer opportunities to assist in caregiving for this increasing number of the population. The concerns of the Chinese elderly are not only utilitarian (functional) but include emotional needs that impact their quality of life. Based on the design theory of responsible innovation and the widely used Internet of Things technology (IoT), it explores relevant forecasting for the design of the healthcare system for the Chinese elderly in the future. From the perspective of a user-centred mindset, it will discuss how to improve and redesign the healthcare system from the view of responsible design.
\end{abstract}

Keywords: elderly challenges, user needs, responsible innovation, IoT technology, caregiving

\section{Introduction}

According to the data released by the China Health Commission (2018), close to 250 million members of the population who are over 60 years old. The emerging demographics indicates the size of aging population will be a challenge, and the market demand for elderly care is significant [1]. With the continuous aging, the elderly will appear the phenomenon of physical function degradation, the decline of organ function, the obvious weakening of the body's resistance to disease, the possibility of suffering from chronic diseases or a variety of complex complications increases, especially the physical and mental function degradation of the elderly is more serious. Elderly living with physical obstacles, that is, the old people who lose or limit the main activity ability in daily life due to old age, weakness, disability, illness, etc., and need to introduce external care. Aging of the population will trigger the increasing of total number of elderly living with physical disabilities [2].

Caring of the elderly is a long process. If the care is not appropriate, for example, in the process of transferring the elderly, it is not only possible for the elderly to be injured, but also for their caregivers to be exhausted physically and mentally with their families if they do not use corresponding assistive devices instead of carrying them by hand. Therefore, the wide application of intelligent nursing assistive devices can not only greatly reduce the physical and mental burden of caregivers, ensure their safety, improve nursing efficiency, but also maintain the self-esteem and safety of the elderly, and slow down the process of disability [3]. " ....as older people are implicitly or explicitly seen as incompetent users of technology" [4]. In the research on the design of elderly living with healthcare service, we searched and studied the literature with the keywords of 'elderly living', 'caregiving' and 'long-term caregiving', and found that the existing literature focused more on the research of "user-centred", especially the caregivers who provide care services in the long-term care process. Noto and Muraki studied the influence on the comfort of the caregiver and the physiological pressure of the caregiver [5]. Some studies also analyzed the relationship between the value of the caregiver and the burden of care and concluded that improving the value of life has a direct impact on the prevention of the increasing burden of care [6].

Three arguments are summarised. First, due to the deepening of the aging of China's population, the related service demand and market will also become diversified. Second, elders need long-term companionship. Elders need companionship more than younger for fighting a sense of isolation, the greater chance of disabilities, more challenges to leading independent living, etc. In addition, long-term care consumes caregivers' physical and mental energy, and the fatigue greatly affects the quality of care they can provide. Third, how makes the healthcare system more inclusive, integrated and multi-purpose is a trend of future development of related disciplines.

The investigation is mainly aimed at 60-70-yearolds in China. The targeted population is all physical abilities, and living independently without any cognitive decline, but have the barrier with electronics use, due to the decline in mental response, as well as the use of negative and fear psychology. Based on the theory of responsible innovation and IoT technology, it forecasts the development trend of China's elderly health care system. We will achieve the following research objectives:

(i) How to encourage the elderly to play an active role in healthcare services and rehabilitation activities. 
How to improve the service efficiency of caregivers to reduce the physical and psychological pressure of caregivers from the perspective of user needs.

(iii) How elderly healthcare service designers and engineers ensure that the design work and future technology is responsible and more intuitive for users.

\section{Challenges}

Technologies, such as the internet of things (IoT), Ambient/Active Assisted Living (AAL) robots and other artificial intelligence (AI), have been shown to have great potential in fostering independent living, improving mental and physical health, and increasing quality of life [7, 8]. At the same time, the IoT technology needs to pay more attention to the psychological demands of the elderly. The major turning point in the second half of life is divided into three parts: retirement, disability, and loss of companionship. For the elderly, three major transitions will cause their separation from society to varying degrees and then cause loneliness [9]. In the latest version of the report, aging 2.0 points to eight grand challenges in the elderly's later years (see Figure 1). They are (i) Engagement and Purpose, (ii) Financial Wellness, (iii) Mobility and Movement, (iv) Daily Living and Lifestyle, (v) Caregiving, (vi) Care Coordination, (vii) Brain Health, and (viii) End of Life [10].

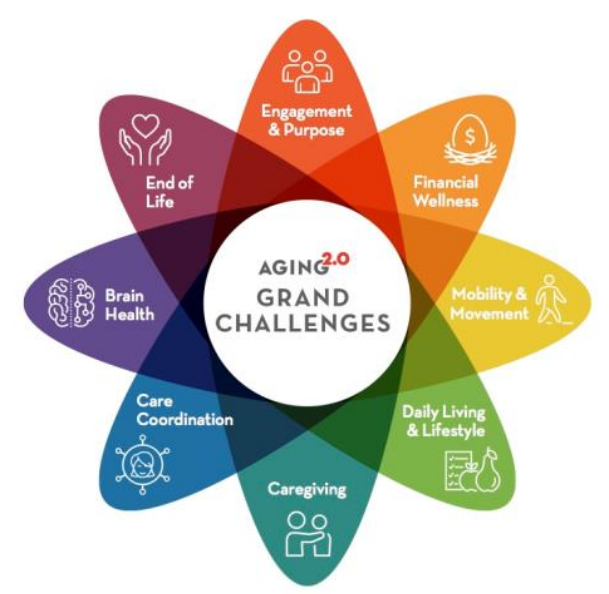

Figure 1. Aging 2.0 Grand Challenges Image from: www.age2.com

Based on the Grand Challenges, we are likely to cause "moral overload" [11]. The moral overload refers to the state that the existing physical and financial conditions cannot meet the realization of a certain value [12]. Also, the individual differences exist in society, culture, class and education level.

Various reasons lead to the phenomenon of "moral overload". The first is the restriction of objective laws, such as technological laws [13] and market laws [14]. Secondly, the external constraints, which refer to the constraints of "social resources" (e.g., economic, cultural, political and even the natural conditions incorporated into society). The third is the limitations of people themselves. In short, people have strong differences in each cognition. Specific limitations can be broken, and the limitations of absolute significance will always exist. Fourth, the results of innovation cannot be predicted. The more creative the original innovation is, the more unpredictable the social chain reaction will be. Even though we can realize the moralizing technology from the value-sensitive design, persuasive technology, innovation and other ways [15], the "Collingridge dilemma" in innovation cannot be avoided for the nonlinear interaction of various factors [16]. Finally, moral luck [17]. Luck is elusive in different individuals; the same moral judgment cannot have the same consequences for all innovative behaviors [18]. We must broaden our definition of innovation. We must test our assumptions about human beings. We must wonder 'who am I excluding?' and allow the answers to change our solutions [19]. According to the eight challenges brought about by aging, we can analyse some problems and phenomena in China's elderly healthcare services.

\subsection{Engagement and Purpose}

According to the report provided by China population and Development Research Center, the proportion of social participation of the elderly in China was 50\% in 2011, 59\% in 2013 and 56\% in 2015 , respectively, which showed an increasing trend in recent years. [20]. The types and proportions of social participation of the elderly in China are as follows: $28 \%$ in social relations and communication, $15 \%$ in chess and card entertainment, $10 \%$ in free and mutual assistance with the same kind of people, $6 \%$ in group physical exercise and $2 \%$ in social organisation activities. The above activities account for most of the social participation. The rest are $1 \%$ of volunteer activities, $0.3 \%$ of school or training courses, $3 \%$ of online activities, $0.5 \%$ of stock speculation, and so on [20].

\subsection{Financial wellness}

The study from Shanghai Aging Science Research Center has found that, in 2015 [21], the average cost of hospitalisation and medicine for the second time of the elderly aged 60 and above is significantly higher than the average level of all patients, and the average cost of medicine for the elderly aged 70-79 is even $65.20 \%$ higher than that of the general patients.

\subsection{Mobility and movement}

Compared with a sensory disability, physical disability not only suppresses the health function of 
the elderly to a greater extent but also harms the emotional cognition of the elderly, specifically, it improves the risk of mental depression and reduces the life satisfaction of the elderly [22].

\subsection{Daily living and lifestyle}

In the study of the daily life of the elderly in China, it was found that due to the difference of medical resources between urban and rural areas and the difference of economic development level between the Eastern and western China, the elderly in urban areas can survive with a disability, so the disability rate of the elderly in urban areas is higher than that in rural areas. Due to the high widowed rate, low income and limited ability to bear the cost of care, the rate of female elderly disability is higher than the male elderly. The simple and convenient living environment layout of the elderly can relatively improve their self-care ability. Compared with 2002, the proportion of the elderly with mild self-care impairment decreased in 2011, but the proportion of the elderly with severe self-care impairment increased, which means that they need high-intensity and high-level long-term care [23].

\subsection{Caregiving}

At present, many pieces of research on the design and application of the intelligent nursing system in China. The existing studies can not only improve the service level of the elderly but also improve the efficiency of nursing and reduce the operating cost of elderly care [24]. The intelligent applications are only in the pilot stage, and they are not widely used. At the same time, no corresponding solution can provide to the barrier of technology use for the elderly.

\subsection{Care Coordination}

Care coordination can be summarised as follows: 1 . The connection between the elderly and the nursing staff and their families; 2 . The connection between the basic nursing facilities; 3 . The connection between the nursing environment formed by the nursing facilities and the nursing needs of the elderly. The essential problems of nursing facilities involved in the following three aspects are 1. The timely communication and exchange of nursing information; 2. The integration of functions among nursing facilities; 3 . The influence of the environment formed by the functions of facilities on the body and mind of the elderly, which is the key issue to the redesign of nursing facilities [25].

\subsection{Brain health}

At present, three kinds of products work in solving Alzheimer's disease in China: exercise products, bracelet monitoring products, and application software products. Exercise products include mental exercise and physical exercise. Its advantage is that it has a broad mass base, but its disadvantage is that its curative effect is not obvious. Bracelet monitoring products can prevent emergencies, but the disadvantage is poor reliability, we have too many uncertain factors. Intelligent products can monitor blood pressure and biological indicators of walking measurement. However, as the elderly have certain barriers to the use of electronic products, it is difficult to assume that technology alone will solve problems without considering the holistic needs and abilities of elders [26].

\subsection{End of Life}

In China, the shortcoming of hospice care is mainly reflected in three aspects: first, the government should pay enough attention to the policy, and promote the development of hospice care from the relevant laws. Second, the elderly people need more professionals and support facilities. At the same time, the understanding of hospice care in China is still uncompleted [27].

\section{Responsible Innovation}

A new product or technology is put into the market, it will meet all kinds of unknown challenges, which is also the complexity in the innovation and design research. Mature and complete innovation work should not only to accurately determine the user group, but also in line with the "user-centred" principle, considering the particularity of the user group, and we also need to design iterations, in the process of finding problems, and finally achieve the sustainability and responsibility of innovation.

\subsection{Healthcare Based on IoT System}

China's current IoT elderly healthcare system is mainly based on mobile healthcare service platform technology. The mobile healthcare has three main components: the portable medical devices, intelligent terminals (phones, tablets, etc.), medical service platform, as shown in Figure 2. Portable medical equipment is responsible for health data acquisition via wireless (Bluetooth, Wi-Fi). Monitoring software on mobile devices is responsible for displaying data and pushing the result to the healthcare service platform but can also receive doctor diagnostic reports pushed from healthcare service platform. The cloudbased medical service platform is a special website, 
and is the core of the whole system, which was built using cloud server technology, cloud storage technology, and cloud push technology and so on [28].

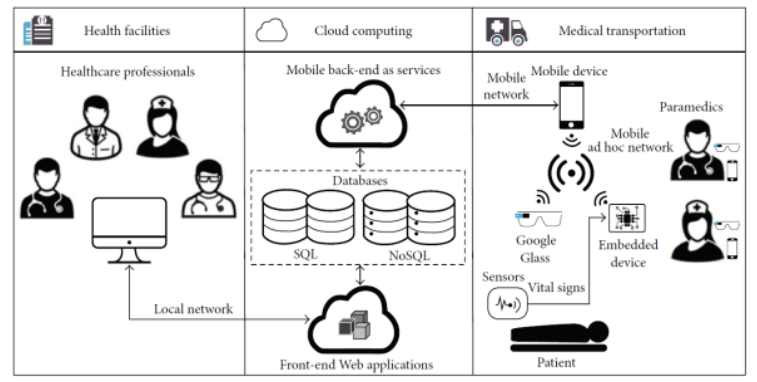

Figure 2. General architecture of the proposed cloudbased mobile system. Image from: Neyem [29]

Using Internet devices, users can view and maintain their health data anywhere, anytime and physicians can check their patients' health condition and pushed the diagnosis report or advice to their patients or patients' family members anywhere, anytime. Also, the system has an online consultation function to facilitate communication between patients and doctors.

Customers-side is mainly responsible for sending task requests getting response data sent by the cloud platform and rendering of services, rarely does the actual computing tasks. The server-side communication interface with the client was designed by the web service way to facilitate data exchange between server and different applications. In health care, the network model of medical records, data, and services contains a highly sensitive scheme [30].

\subsection{Problems and Responsible Innovation}

The intelligent healthcare management platform based on remote monitoring and the IoT technology provides the elderly with more humanised experience and more reliable medical care services. It can improve nursing efficiency, reduce nursing costs, reduce nursing disputes, improve medical management and service level, and create good social and economic benefits for the hospital [24].

The conditions are based on the premise that the elderly have a clear and healthy brain cognition, and no barrier to the use of technology products. At the same time, due to the degradation of physical function, disease, living environment and the change of interpersonal relationships, the old people have a psychological state of loneliness, depression, paranoia, inferiority and so on. In dealing with people

\footnotetext{
${ }^{1}$ The sent-down, rusticated, or 'educated youth' (Chinese: 知識青年), also known as the 'Zhiqing' , were the young people who- - beginning in the 1950s until
}

and things, the elderly often seek stability in everything, worry about mistakes, heavy psychological burden [26]. Besides, the retirement syndrome, which is a series of psychological diseases caused by the elderly inability to adapt to the new lifestyle [31].

Engineers and designers intend to provide users with more, better and more convenient services. However, they lack sufficient understanding of the responsibilities of innovation and reconstruction of innovation values. It contains the evaluative moral dimension and epistemological knowledge dimension, including innovation evaluation and innovation knowledge [32]. The elders are different from the general user groups, we should consider its particularity, such as: cognitive difficulties caused by the decline of physical function, obstacles to the use of new technology and related psychological problems.

\section{Survey and Feedback}

Understanding the perspective and social context of the user is one of the most important parts of design and design education [33]. The purpose of survey is to define the target population's daily life habits, the composition of social relations, the user experience of electronic products and the satisfaction of social medical system. According to the survey results, we analysed the late life experience of the target population and whose concerns, as well as the related mental demands for new type healthcare technologies. It is worth noting that the following seven interviewees are aged between 60 and 70 years old without serious physical diseases and have no significant physical or cognitive decline. The respondents were collected 7 persons who have the experience of the 'set-down' 1 in Jinzhou District, Dalian City, Liaoning Province, China. Before retirement, they were engaged in different jobs and had different incomes. Table 1 summarises the interviewees' background information. According to the theory of the Aging Grand Challenge 2.0 (2018), the author designed eleven questions to investigate the concerns for the information-based healthcare system.

As reflected in Table 2, it is difficult for the elderly to make new friends as a long-term and stable social relationship. Since they feel more vulnerable than they did when they were younger, some means of fraud are more threatening than before, so they hold the attitude of "seeking stability in everything".

Table 3 shows that most of the activities of interviewees are around a certain group, such as old friends, old classmates, old comrades in arms and so on. At the same time, children are an unavoidable

the end of the Cultural Revolution, willingly or under coercion-left the urban to live and work in rural areas. 
topic. Even after retirement, they still care about children's growth.

Table 4 shows that retired people are very calm, in order to help their peers not to worry about personal gains and losses. For old friends, they will also release their enthusiasm to help each other.

Table 5 shows that all the interviewees live in the city, have a certain economic foundation, and have corresponding insurance to pay for medical expenses. But the data does not represent a rural sample.

Table 6 shows that the interviewees basically tend to entertain and chat in the use of online electronic products. They are cautious about the use of deeper products.

Table 7 shows that interviewees have deep barriers to use health applications. Most respondents indicated that too fast development makes elderly difficult to change the existing lifestyle.

Table 8 shows that after retiring, elders spend most of their free time on leisure and entertainment.

Table 9 shows none of the interviewees had the experience of employing caregivers, and they did not know much about the caregivers. At the same time, respondents also care about the cost of hiring caring workers.

Table 10 shows most medical expenses can be paid by medical insurance. But depending on the drug, the cost will change. It is worth noting that for the non-income group, the previous premium is a big expense.

Table 11 shows the most interviewees have a positive attitude towards physical exercise. Many elderly people take part in physical exercise for the purpose of keeping healthy and reducing medical cost. Some interviewees who simply like physical exercise and enjoy outdoor sports and the natural environment.

Table 12 shows traditional Chinese parents love their children selflessly. They have their own family mission and want to make their children better than themselves. The growth of children is the biggest concern of parents, and the growth of children has also been unconditionally supported by parents. The parents are unwilling to bring unnecessary troubles and troubles to their children. On the issue of old age life, the old people want to deal with it by themselves as much as possible.

From the survey of the respondents, the study found that elders are eager to seek stability in everything and pay attention to long-term and stable social relations. For health applications, you do not want to have too much difficulty. In the future life of the elderly, seeking independence, not willing to bring too much trouble to their children. For the medical service system, seek a stable social medical and pension system, and do not want to spend too much on it. As illustrated in Figure 3, shows the territory of elderly concerns.

\section{Discussion}

Blok mentioned, "responsible innovation = general innovation + ethical considerations + integration of stakeholders in society" [34]. The difference between responsible innovation and open innovation lies in the further expansion of the subject and object of responsibility in innovation [35]. In nature, responsible innovation emphasizes positive responsibility but does not ignore negative responsibility [36]. Many scholars advocated the Internet of things health management platform for the elderly to provide efficient, fast and convenient positive responsibility, but for the barriers of using technology products, such negative responsibility has not been concerned. At the domain level, on the one hand, responsible innovation is not only innovative practice but also a new understanding of the responsibility and the reconstruction of innovation values [34]. The innovative design of the elderly healthcare management platform should include innovation evaluation and innovation knowledge. Finally, on the strength level, responsible innovation certainly pays attention to soft responsibility such as moralities, but also pays attention to hard responsibility such as legal responsibility and system responsibility [37]. With the help of high-tech products to serve the elderly, the ethical factors should be emphasised, such as personal information security and privacy protection.

Compared with the framework of Aging2.0 (see Figure 1), we found that the elderly in China have unique challenges different from other countries. Due to the unbalanced development of China's East and West, not all the elderly can enjoy a perfect medical insurance system. Secondly, due to the uncertainty of the future elderly life, most of them have the habit of saving, and they are cautious about the related financial services. Thirdly, China's elderly care service is still in its infancy, and we still have a lot of work to be improved, whether it is hardware services or national awareness. Fourthly, the joint platform of the elderly related medical industry needs to be improved.

From the perspective of caregivers, we should also pay attention to the user experience of the service side, improve work efficiency and improve working conditions in line with the idea of 'people-oriented'. On the other hand, the Chinese elderly pay attention to social relations and are eager to help others of the same kind, which shows that the elderly pay attention to social group relations. The elderly in China is willing to study traditional Chinese medicine health preservation and uncertainty about future medical services and pay close attention to their own physical condition and physical exercise. 
Table 1. Interviewee composition

\begin{tabular}{ccc}
\hline Interviewee & Age & Job before retiring \\
\hline 1 & 68 & Technician in oil field \\
2 & 67 & Cartographer \\
3 & 66 & AC technician \\
4 & 68 & Insurance agent \\
5 & 67 & Property agent \\
6 & 69 & Civil servant \\
7 & 66 & Teacher in high school \\
\hline
\end{tabular}

Table 2. Question 1: What is your main social relationship?

\begin{tabular}{cr}
\hline Interviewee & Responding \\
\hline 1 & Classmates, colleagues before retiring, friends, sent-down youth. \\
2 & Sent-down youth, comrades in arms, classmates. \\
3 & Friends, colleagues before retirement, sent-down youth. \\
4 & Past classmates, relatives, and friends. \\
5 & Colleagues before retiring, relatives, old classmates. \\
6 & Past colleagues, old classmates, children. \\
7 & Most of them are old classmates. \\
\hline
\end{tabular}

Table 3. Question 2: What are your main activities after retiring?

\begin{tabular}{cr}
\hline Interviewee & Responding \\
\hline 1 & Drinking tea, chatting, touring, and fitness with friends. \\
2 & Photography, SPA, shopping, public welfare activities, chatting, touring with girlfriends. \\
3 & Watch news on TV, have dinner, touring, playing mahjong, and poker with friends. \\
4 & Exchange investment and financial expertise online, chat with friends. \\
5 & Concerning about the development of children's growth, gathering with old friends and \\
6 & classmates, chatting with friends online. \\
7 & Playing poker online, chatting with friends and drinking tea.
\end{tabular}

Table 4. Question 3: Would you like to help each other with your peers?

\begin{tabular}{cc}
\hline Interviewee & Responding \\
\hline 1 & Friends will help each other when they have difficulties. \\
2 & Yes, it will help if I have any difficulty. This is the continuation of the past friendship. \\
3 & Yes, retired people have a peaceful mind and do not care about personal gain or loss. \\
4 & Yes, I would like to use my professional experience to help my friends with pension \\
insurance related issues.
\end{tabular}


Table 5. Question 4: Does the usual medical expenses account for the main part of the living expenses?

\begin{tabular}{cc}
\hline Interviewee & Responding \\
\hline 1 & It does not cost too much. Most of the expenses were covered by medical insurance. \\
2 & Affordable. \\
3 & It can be cost by quite cheaply. \\
4 & Medical insurance can cover, but some drugs I must pay it by myself. \\
5 & I can afford it. \\
6 & I have a medical card(insurance), which can be reimbursed. \\
7 & Medical insurance could afford it. \\
\hline
\end{tabular}

Table 6. Question 5: Are you familiar with network electronic products or services? Which ones do you most commonly use?

\begin{tabular}{|c|c|}
\hline Interviewee & Responding \\
\hline 1 & Chatting tools and shopping platform. \\
\hline 2 & $\begin{array}{c}\text { Usually like to watch movies on the Internet, also commonly used some chatting tools. } \\
\text { But for network electronic products, I am more cautious. Last year, I failed to invest in } \\
\text { an online lending platform and lost } 150,000 \text { Yuan }(\$ 20,000) \text {. I have bad experience in } \\
\text { network electronic products. }\end{array}$ \\
\hline 3 & Online mahjong, poker, and chatting tools. \\
\hline 4 & $\begin{array}{c}\text { Most of the apps used are about banking services and life services. I seldom play } \\
\text { online games. Too hard for me. }\end{array}$ \\
\hline 5 & I usually use my cell phone to watch movies, watch news and chat. \\
\hline 6 & In addition to talking, I seldom use mobile phones. \\
\hline 7 & $\begin{array}{l}\text { I usually use news app, but seldom other apps. If I have the strange and necessary } \\
\text { apps, I will ask my children to teach me how to use them. }\end{array}$ \\
\hline
\end{tabular}

Table 7. Question 6: Do you know about health apps? Which ones do you use?

\begin{tabular}{cc}
\hline Interviewee & Responding \\
\hline 1 & Due to the age, the understanding is very limited. That is the strength of young people. \\
2 & "WeRun", the product of WeChat. \\
3 & Learning is very limited. \\
4 & Rarely used. \\
5 & It is hard for me to enter the information of related services due to my poor eyesight. \\
6 & Rarely used. \\
7 & Basically no, I do not need it. \\
\hline
\end{tabular}

Table 8. Question 7: After retirement, what are mental labor or mental activities?

\begin{tabular}{cc}
\hline Interviewee & Responding \\
\hline 1 & Playing mahjong, poker. \\
2 & Guessing riddles and playing games online. \\
3 & Playing games and Mahjong Online. \\
4 & Calculating the daily expenses. \\
5 & Playing games online. \\
6 & Learning "Health-preserving of Traditional Chinese Medicine". \\
7 & Reading books, teaching children and watching news. \\
\hline
\end{tabular}


Table 9. Question 8: Do you have any experience in hiring caregivers and are you satisfied with its experience?

\begin{tabular}{lc}
\hline Interviewee & Responding \\
\hline No. 1 & Not have. \\
No. 2 & Not have. \\
No. 3 & Not have. Nurses will hele me even if I am in hospital. \\
No. 4 & Not have. But I guess I am going to have in future. \\
No. 5 & Not have. I do not have any hospitalisation experience. \\
No. 6 & Not have. But my daughter has the experience when she was pregnant. \\
No. 7 & I do not want to spend money on care. I will find my children if necessary. \\
\hline
\end{tabular}

Table 10. Question 9: How is your medical expenses made up?

\begin{tabular}{|c|c|}
\hline Interviewee & Responding \\
\hline No. 1 & The State takes up $80 \%$ of the total, and some individuals take part. \\
\hline No. 2 & $\begin{array}{l}\text { The state accounts for } 80 \% \text {, but according to individual medical needs, some drugs are } \\
\text { personal buying, and the proportion will change. }\end{array}$ \\
\hline No. 3 & Under normal conditions, the state accounts for $80 \%$ (social insurance). \\
\hline No. 4 & $\begin{array}{c}\text { Medical insurance can provide a good guarantee, but for the non-income group, the } \\
\text { previous premium is a big expense. }\end{array}$ \\
\hline No. 5 & Most of them are covered by medical insurance, and a few are covered by themselves. \\
\hline No. 6 & $\begin{array}{c}\text { It is rarely used for medical expenses. I usually pay attention to exercise and have few } \\
\text { serious diseases. }\end{array}$ \\
\hline No. 7 & Except for individual drugs, they can be reimbursed by medical insurance. \\
\hline
\end{tabular}

Table 11. Question 10: How do you understand the exercise of the elderly?

\begin{tabular}{cc}
\hline Interviewee & Responding \\
\hline $\begin{array}{l}\text { No. } 1 \\
\text { No. } 2\end{array}$ & It is common sense that life depends on movement. I like going to the gym. \\
$\begin{array}{l}\text { No. } 3 \\
\text { No. } 4\end{array}$ & I like aerobics. I like to walk in the wild, breathe fresh air and get close to nature. \\
No. 5 & Constantly exercise can improve the quality of life for the elderly. \\
No. 6 & Life depends on movement. \\
No. 7 & The habit of exercise has been formed since I was young. \\
\end{tabular}

Table 12. Question 11: Do children often look after and accompany you?

\begin{tabular}{lr}
\hline Interviewee & Responding \\
\hline No. 1 & Limited. If I lose my mobility, I will go to a nursing home. \\
No. 2 & It is inconvenient for children to be away from home. \\
No. 3 & Children and their spouses have own jobs, it is impossible to look after for the elderly. \\
No. 4 & Constantly exercise can improve the quality of life for the elderly. \\
No. 5 & Children have their own families and do not want to take up too much of their time. \\
No. 6 & Children are abroad, they seldom go back to China except for holidays. \\
No. 7 & The kid's work is very busy, but we keep in touch by telephone.
\end{tabular}

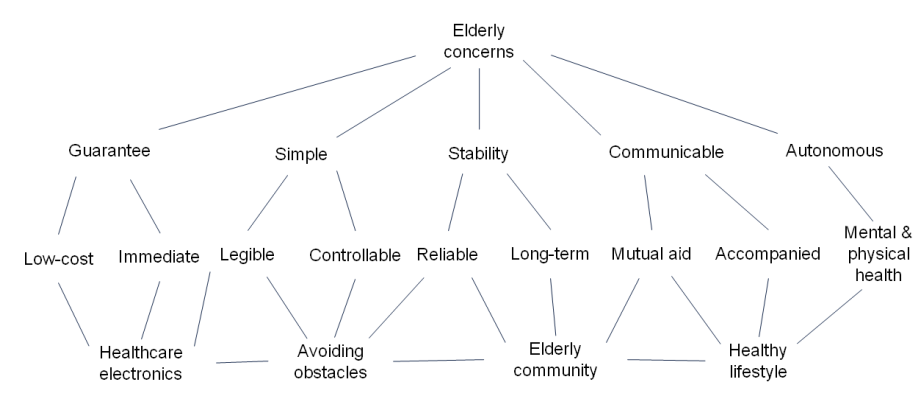

Figure 3. The framework of elderly concerns from the survey Image from: author 


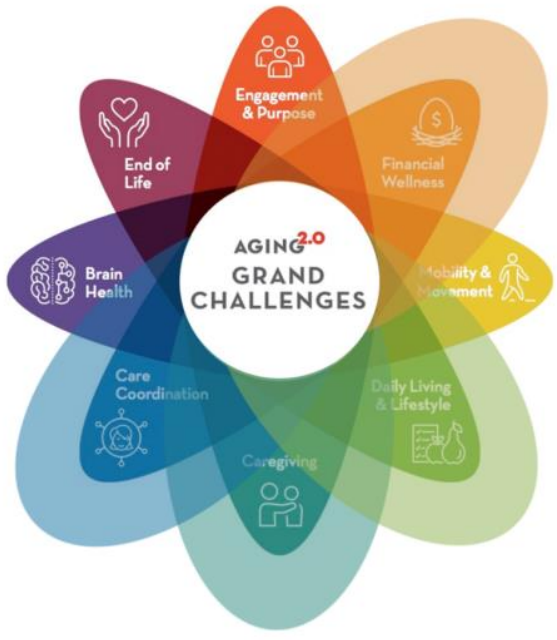

Figure 4. China Aging Grand Challenges based on the Aging 2.0 Framework Image from: author

At the same time, the elders are willing to participate in social activities and mental exercise, and the incidence of Alzheimer's disease is relatively low [26]. Finally, China's elderly system achieves autonomous, independent and high participation in their later life by a healthy and low-stress lifestyle. Figure 4 shows the difference between the unique China elderly challenge concerns and Aging 2.0 Framework.

\section{Recommendation}

According to the survey results, we suggest that in the future, the healthcare management platform for the elderly in China should be improved from the following aspects:

\subsection{Engagement and Purpose}

Table 2, 3, 4 and 11 show the unique living habits and psychological state of the elderly, the healthcare network platform should more improve the degree of participation, especially encourage the elderly to have their sense of belonging, such as chat groups and online community platforms. The network community will provide the elderly a platform to share the user experience of relevant products and encourage each other to participate in rehabilitation and treatment.

\subsection{Financial Wellness}

Table 5 and 10 shows the different financial status of the elderly retirees. The state should issue corresponding policies to subsidize the medical expenses of the elderly according to the specific financial situation of the elderly. So that the elderly has no worries in their later life. We need to design a multi-dimensional social pension insurance system according to the different economic basis of the elderly, to increase the coverage of the whole social pension system.

\subsection{Mobility and Movement}

Table 7 proves that the retired elderly is not unfamiliar with technology products. We have reason to believe that technology can help the elderly in their daily activities. In the design of the elderly mobility assistance tools, we should develop towards the direction of intelligence, network, and information. For the elderly with mobility obstacle, relevant emergencies will be monitored in real-time.

\subsection{Daily Living and Lifestyle}

The elderly is not unfamiliar with technology products, but they still have doubts, especially in terms of user privacy and network security (see Table 6). According to the unbalanced development of urban and rural areas in China, the relevant policies of medical care and pension should be focused on. For the promotion of new technology products, we should not only meet the elderly's acceptance of new technology products but also pay attention to related moral issues, such as user privacy, network information security and so on. For the characteristics of the elderly, we should have a better understanding of their psychological demands.

\subsection{Caregiving}

The study found that most of the elderly have no experience in caregiving service for a variety of reasons, most of them are unwilling to spend too much, used to having family accompany, and do not want to fill in unnecessary trouble (see Table 9). In the future practice of the healthcare management system based on the IoT system, besides the design of related hardware managers should consider the 'human' factor. In addition to care-receiver, the 'human' factor should also pay attention to the physical and emotional influence of the caregiver. Caregivers should avoid repetitive high physical labor, simplify nursing skills, and reduce the process of human handling.

\subsection{Care Coordination}

According to Table 6 and Table 7, due to the changes of the times and the limitation of personal 
knowledge, the elderly has certain doubts and barriers to the use of electronic equipment in caregiving service. At present, with the support of the IoT technology, the medical information of the caregivers can be fully communicated with the medical institutions promptly. Also, users' privacy and information security should be respected to a greater extent. Users should also have more autonomy in information collection, to establish a complete trust system between service providers and users.

\subsection{Brain Health}

The characteristics of the needs of the elderly are that the common operations do not change the elderly's inherent living habits as much as possible, reduce the new content that needs to be learned, and integrate the familiar things that they generally recognize into the innovation, which will help to stimulate the empathy effect and obtain the recognition of the elderly for medical services. The trend of "Internet + elderly healthcare" has gradually become the mainstream in China. The design of the screen user interface for the elderly should follow the following three principles: 1) the simplicity of operation. The interface should be simple and clear, avoid a repeated operation, and decrease the memory burden of the elderly. 2) Identification of information. Based on the physiological function of the elderly, especially the deterioration of the brain, the product interface should be transformed into the familiar styles and functions of the elderly. 3) Add inquiry function and editable function, so that elders have more autonomy in the identification of product interface.

\subsection{End of Life}

Combined with the characteristics of the retired elderly people (see Table 7), the elderly hospice care can be improved from: 1 ) in policymaking, in addition to making relevant laws for the elderly to promote the development of hospice care, the rights and interests of caregivers and service providers should also be considered. 2) We should strengthen the whole society's understanding of the hospice care for the elderly, strengthen efforts to train relevant technical personnel, and improve the standards of software and hardware.

\section{Conclusion}

Given the research on the theory of responsible innovation and the IoT technology, w the challenges surrounding the elderly care services and predicted the development trend of the elderly health care system in China were evaluated. We realise that in the innovation activities, both the subjective and the objective sides of service should be satisfied with the relevant interests, to achieve the final inclusive results.

Based on the real needs and challenges of the elderly and caregivers in China, it puts forward the innovative principles of medical services for the elderly in the future. The research conclusions are summarized as follows: 1) in the future, the medical service interface of the Internet of things should have a higher affinity for the elderly. According to the user characteristics of the elderly, simplify the use function to achieve the active interaction between the service subject and the object. 2) We should reduce the repeated physical labor of caregivers and relieve the psychological pressure. At the same time, from the formulation of relevant policies and regulations and the construction of the whole medical industry, the whole society should also give more attention and support to the caregivers. We need to examine the extent to which users accept new things while innovating. Elders are different from the general young user groups; we should consider its particularity.

The COVID-19 (Novel Coronavirus), which broke out in late 2019, has globally impacted the millions of lives. All ages, industries, and classes must shift their focus of life to fighting the epidemic. At the same time, all countries in the world adjust and improve their public health policies according to the epidemic situation. The interviewees did not consider the impact of the relevant factors of the epidemic. The interview questions were also designed according to the lifestyle before the outbreak. Based on the prospect of the epidemic and its impact on people's lives, the author will explore how the elderly can overcome the fear of the epidemic and find their ambitions in life in the future work.

\section{References}

[1] Analysis of disabilities and care needs of the elderly in urban and rural China', National Health Commission, Beijing, 2018, p. 30.

[2] Cao. X. (2016), 'A study on the long-term care insurance system for the disabled in China -- Based on the perspective of financial equilibrium', Social Sciences Literature Press, Beijing, 2016, pp. 17-21.

[3] Mortenson W B, Demers L, Fuhrer M J, Jutai J W, Lenker J, DeRuyter F. (2013) 'Effects of an assistive technology intervention on older adults with disabilities and their informal caregivers: an exploratory randomized controlled trial', Am J Phys Med Rehabil, 2013, 92(4), pp. 297-306.

[4] J Bergschold, L Neven, A Peine, (2020) 'DIY gerontechnology: circumventing mismatched technologies and bureaucratic procedure by creating 
care technologies of one's own', Sociology of Health \& Illness, 42(2 2020 ISSN 0141-9889, pp. 232-246.

[5] H. Noto, S. Muraki. (2014) 'Effect of rear-wheel operation of a manual wheelchair on user's riding comfort and helper's physical strain while navigating steps', Biomedical Soft Computing and Human Sciences, Japan, 2014, 19(1), pp. 17-22.

[6] K Okamoto, Y Momose, A Fujino, Y Osawa. (2007) 'Life worth living for caregiving and caregiver burden among Japanese caregivers of the disabled elderly in Japan', Archives of Gerontology and Geriatrics, 2007 (48), pp. 10-13.

[7] Mihailidis A., Carmichael B., Boger J. (2004) 'The use of computer vision in an intelligent environment to support aging-in-place, safety, and independence in the home', IEEE Trans. Inf. Technol. Biomed. 2004 (8), pp. 238-247.

[8] Chiu C J., Hu Y H, Lin D C, Chang, F Y, Chang, C S, Lai, C F, (2016) 'The attitudes, impact, and learning needs of older adults using apps on touchscreen mobile devices: Results from a pilot study', Computers in Human Behavior, Volume 63, October 2016, pp. 189-197.

[9] S. Wildevuur, D. Dijk, T. Hammer-Jakobsen. (2013) 'Connect: design for an empathic society', BIS Publications, The Netherlands, 2013, pp. 139-142.

[10] 'Aging2.0's Grand Challenges is a global initiative to drive collaboration around the biggest challenges and opportunities in aging.', https://www.aging2.com/grandchallenges/ (Access Date: 21 June 2020).

[11] R. Owen, J. Bessant, M. Heintz. (2013) 'Responsible innovation: managing the responsible emergence of science and innovation in society', A John Wiley \& Sons Inc., United Kingdom, 2013, pp. 77-82.

[12] T. Kuran, (1998) 'Moral overload and its alleviation', 'Moral Overload and Its Alleviation,' in Avner Ben-Ner and Louis Putterman (eds.), Economics, Values, and Organization, Cambridge University Press, New York, 1998, pp. 231-266.

[13] Chen C. (2012) 'Introduction to Philosophy of technology’, Beijing, China: Science Press.

[14] E. Bakker, C. Lauwere, Hoes, A.-C. Beekman, V. (2014) 'Responsible research and innovation in miniature: Information asymmetries hindering a more inclusive "nanofood" development', Science and Public Policy, United Kingdom, 2014, 41, pp. 294305.
[15] S Soltanzadeh. (2012) 'Peter-Paul Verbeek's Moralizing Technology: Understanding and Designing the Morality of Things', NanoEthics Springer, Netherlands, 2012, Volume 6, Issue 1, pp. 77-80.

[16] Lv N. (2011) 'Discrimination of "double-edged sword" in science and technology', Philosophy research, Beijing, 2011 (7), pp. 106- 109.

[17] Williams, B. (1981) 'Moral Luck', Cambridge University Press, Cambridge, 1981, pp. 20-39.

[18] Nagel, T. (1991) 'Mortal Questions', Cambridge University Press, Cambridge, 1991. p. 25.

[19] Holmes K. (2018) 'Mismatch: how inclusion shapes design', The MIT Press, Cambridge, Massachusetts, 2018.

[20] Li Y., Lu J., (2018) 'Social participation of the elderly in China: connotation, current situation and challenges', Population and family planning, Beijing, 2018, 11, pp. 14-17.

[21] Shanghai aging science research center. (2015) 'Shanghai aging population and cause monitoring statistics' [EB / OL]. [2017-12-01]

[22] Zhang Y, Ge Z, (2017) 'The influence of different disability status on the quality of life of the elderly in China', Nanjing, Population and Society, Nanjing University of Posts and Telecommunications, Nanjing, China, Oct 2017, 33(4), pp. 33-42.

[23] Jiang X, Wei M, (2015) 'Activity of daily living of the Chinese oldest-old and its change between 2002 and 2011', Population \& Development. 21(2), 2015, Beijing, University of Beijing, pp. 93-100.

[24] Zhou C, Gao Y, Qu H, Cui M, Sun Z, (2015) 'Design and application of an intelligent nursing system in the geracomium', China Medical Devices, Beijing, 2015. 30(9), pp. 76-78.

[25] Cao X, (2006) 'Study of systematic design of basic nursery facilities for senior citizens', Zhuangshi, Beijing, University of Tsinghua, 2006, 5, pp. 117-118.

[26] Guo Y, (2017) 'The prevention and treatment of the elderly Alzheimer's educational care design research', Chongqing, Packing engineering, Chongqing, 2019 (12), pp. 171-175.

[27] Cao Q, (2015) 'A summary of the research on the hospice care of the elderly', Business, Chengdu, 2015, 52, p. 22. 
[28] Gao. Z Q, He. L S, Tian H, (2015) 'A cloud computing based mobile healthcare service system', Proc. Of the 2015 IEEE 3rd International Conference on Smart Instrumentation, Measurement and Applications (ICSIMA 2015), pp. 24-25.

[29] A Neyem, M J. Carrillo, C Jerez, G Valenzuela, N Risso, Jose I. Benedetto, J S. Rojas-Riethmuller, (2016) 'Improving Healthcare Team Collaboration in Hospital Transfers through Cloud-Based Mobile Systems', Hindawi Publishing Corporation, Mobile Information Systems, Volume 2016, Article ID 2097158, 14, pp. 1-15.

[30] K. Rabieh, K. Akkaya, U. Karabiyik, J. Qamruddin, (2018) 'A secure and cloud-based medical records access scheme for on-road emergencies', Proc. 15th IEEE Annu. Consum. Commun. Netw. Conf. (CCNC), Jan. 2018, pp. 1-8.

[31] Deng A, (2014) 'One should pay attention to psychological illness syndrome: retirement', Shanghai Society for Retired Staff Management Best Selected Papers in 2014, 2014(8). pp. 7-11.

[32] Grunwald A. (2011) 'Responsible innovation: bringing together technology assessment, applied ethics, and STS research', Enterprise and Work Innovation Studies, Lisboa 2011, 7(7) pp. 17-19.

[33] Koppen E and Meinel C. (2012). 'Knowing People: The Empathetic Designer.' Design Philosophy Papers, 10(1): 35-62.

[34] Blok V, Lemmens P, (2015) 'The emerging concept of responsible innovation', Responsible Innovation 2: Concepts, Approaches, and Applications. Cham: Springer, 2015, pp.19-35.

[35] Liu Z, (2018) 'Overall-responsibility: The Essence of Responsible Innovation', Studies in Dialectics of Nature, Beijing, 34(10) pp. 40-45.

[36] De Saille S, Medvecky F, (2016) 'Innovation for a steady state: a case for responsible stagnation', Economy and Society, 2016, 45(1): pp 1-23.

[37] Liu Z, (2015) 'Summary of responsible innovation research: background, current situation and trend', Science \& Technology Progress and Policy, 32(11) Jun., Wuhan, 2015, pp. 155-160.

\section{Acknowledgements}

We wish to thank the support from Prof. Stanley Ruecker (School of Art + Design) and Professor Wendy Rogers (College of Applied Health Sciences) at the University of Illinois at Urbana-Champaign, for her thoughtful suggestions. 